\title{
Open retropubic radical prostatectomy
}

\author{
Ryan Pereira $^{1,2}$, Andre Joshi ${ }^{1,3}$, Matthew Roberts ${ }^{1,2,4}$, John Yaxley ${ }^{2,5}$, Ian Vela ${ }^{1,2,3,6}$ \\ ${ }^{1}$ Department of Urology, Princess Alexandra Hospital, Brisbane, Australia; ${ }^{2}$ Faculty of Medicine, The University of Queensland, Brisbane, Australia; \\ ${ }^{3}$ Queensland University of Technology, Australian Prostate Cancer Research Centre, Brisbane, Queensland, Australia; ${ }^{4}$ Nepean Urology Research \\ Group, Kingswood, Australia; ${ }^{5}$ Department of Urology, Royal Brisbane and Women's Hospital, Brisbane, Australia; ${ }^{6}$ Translational Research Institute, \\ Brisbane, Australia \\ Contributions: (I) Conception and design: I Vela, M Roberts, R Pereira; (II) Administrative support: None; (III) Provision of study materials or \\ patients: None; (IV) Collection and assembly of data: None; (V) Data analysis and interpretation: None; (VI) Manuscript writing: All authors; (VII) \\ Final approval of manuscript: All authors. \\ Correspondence to: Dr. Ian Vela. Department of Urology, Princess Alexandra Hospital, Woolloongabba 2747, Australia. Email: ian.vela@health.qld.gov.au.
}

\begin{abstract}
Radical prostatectomy $(\mathrm{RP})$ is a common treatment choice for localized prostate cancer. While there is increasing utilisation of robotic assisted RP in some centres, open RP (ORP) remains well established and commonly performed in many parts of the world. The goals of modern ORP are to remove the prostate en-bloc with negative surgical margins, while minimising blood loss and preserving urinary continence and erectile function. We present a technical review of ORP incorporating contemporary techniques for control of the deep venous complex, additional haemostatic measures, nerve-sparing and vesicourethral reconstruction.
\end{abstract}

Keywords: Prostate cancer; radical prostatectomy (RP); prostatectomy, retropubic; surgery

Submitted Jun 20, 2019. Accepted for publication Sep 04, 2019.

doi: $10.21037 /$ tau.2019.09.15

View this article at: http://dx.doi.org/10.21037/tau.2019.09.15

\section{Introduction}

Radical prostatectomy (RP) is a common treatment choice for localized prostate cancer (1-4). In 1947, Millin described the first retropubic approach for performing this operation following earlier reports of the perineal approach by HughHampton-Young in 1905 (5-7). Historically, both operations were associated with significant intra-operative and postoperative morbidity and mortality $(5,8)$. During the last three decades, technical modifications and refinements have improved clinical and functional outcomes after RP $(8,9)$. Additionally, lessons learnt from the laparoscopic and robotic approach have also been utilised and implemented to open RP (ORP) (10). Broadly, the goals of modern ORP are to remove the prostate $e n-b l o c$ with negative surgical margins, minimise blood loss with preservation of urinary continence and potency $(8,11)$. In the hands of an experienced surgeon, the operation can generally be performed in 2 to 4 hours (depending on factors such as nerve-sparing and lymphadenectomy), through a lower midline or Pfannenstiel incision less than 15 centimetres in length, commonly with only 2 to 3 days of hospitalisation $(12,13)$.

Furthermore, prostate-specific antigen (PSA) screening has resulted in a dramatic downstage migration, favouring the detection of localised, organ confined disease (14). This has increased the probability of organ confined disease on pathology and increased the number of men suitable for nerve-sparing techniques, resulting in a higher demand for RP as the preferred treatment choice across many jurisdictions $(5,14,15)$. The objective of this manuscript is to review established and newer techniques as well as oncologic and functional outcomes of ORP including technical modifications. The authors recognise that here are many different methods and techniques for each specific step, and seek to present a commonly used approach, which can be modified according to surgeon preference and training. 


\section{Operative steps}

\section{Preoperative considerations}

A preoperative assessment of the patients existing bladder and sexual function is important. Past surgical and medical history is attained, in particular, prior pelvic or abdominal surgery, pelvic radiotherapy, transurethral surgery and laparoscopic inguinal hernia repair with mesh, all of which may affect perioperative and functional outcomes. A review of preoperative PSA, biopsy results, prostate size and staging (including multiparametric magnetic resonance imaging (mpMRI) of the prostate which is routinely performed by the authors) help with informed consent and the discussion on expected post-operative recovery course and potential complications. Prior to surgery blood group and hold and updated biochemical/haematological parameters should be attained.

In the operating theatre, ORP is performed under general anaesthesia with prophylactic antibiotics, pressure area and venous thromboembolic prevention as per institutional protocol or surgeon preference. If preferred, relative hypovolaemia or low venous pressure anaesthesia with limited crystalloid fluid replacement intraoperatively is maintained until the dorsal venous complex (DVC) is controlled, in consultation with the anaesthetist (16). A cell saver can facilitate autologous blood recovery and decrease intra-operative transfusion risk (10).

\section{Preparation}

The patient is positioned supine with the suprapubic area over the table break. Some surgeons place the patient in subtle hyperextension, in isolation, or in combination with a Trendelenburg position to improve exposure to the pelvis. Care must be given to avoid excessive hyperextension of the operating table, especially in obese patients and patients with pre-existing spinal pathology or surgery. Sterile skin preparation and draping is then performed, followed by insertion of 16 or 18 French (Fr) indwelling catheter (IDC) with $15-30 \mathrm{~mL}$ of water in the balloon. A right-hand dominant surgeon preferentially stands on the patients left to allow optimal access to the pelvis with their preferred hand. During ORP, excellent visualisation is critical for both cancer control and functional outcomes and may be maximised with the use of $2.5 \times$ loupes, with a focal length set at the extent of surgeon arm length (due to the depth of the pelvis and nature of the surgery) and a headlight.

\section{Exposure and defining the space of Retzius}

A lower midline or Pfannenstiel incision is made to allow an extraperitoneal approach and the space of Retzius is developed with careful blunt dissection. Care is taken to gently mobilise the lateral iliac and obturator vessels and pelvic floor off the prostate in order to prevent inadvertent bleeding through avulsion of small perforating vessels. The vasa deferentia bilaterally are preserved and displaced superiorly through gentle blunt finger dissection into the retroperitoneum in order to place a thin malleable retractor into this space. This is critical in order to allow access to the bifurcation of the common iliac vein as part of an adequate pelvic lymph node dissection (if being performed). A fixed retractor, such as a Book-Walter, Omnitract or Turner Warwick, is used to displace the bladder and peritoneum cephalad and two or four body wall retractors are placed laterally at the apex of the wound caudally.

\section{Endopelvic fascia and puboprostatic ligaments}

Following ligation or control with diathermy of the superficial DVC and removal of periprostatic fat, the endopelvic fascia bilaterally are opened at the reflection of the prostate with the pelvic side wall with diathermy or scissors. Care must be taken to avoid the underlying periprostatic venous plexus by keeping the incision lateral to the prostate as medial incisions can result in bleeding. The endopelvic incision is extended anteriorly and medially to the puboprostatic ligaments. Accessory pudendal vessels are sometimes encountered at this point and should be preserved if possible, to aid postoperative erectile function recovery. The prostate is then displaced posteriorly with a sponge stick to allow division of the puboprostatic ligaments with Metzenbaum scissors. The pubo-urethral extensions should be spared, where possible, for structural support to the external sphincter aiding continence $(9,17)$. Gentle blunt dissection of the pelvic floor musculature off the lateral and apical aspects of the prostate is performed with careful attention not to over dissect the apex of the prostate which can affect postoperative continence recovery.

\section{Initial apical dissection in preparation for nerve-sparing}

At this point the lateral prostate fascia is incised and initial mobilisation of the neurovascular bundles (NVBs) off the anterior and lateral prostate apex is performed. A high incision on the anterior portion of the prostatic fascia near 
the 10 and 2 o'clock positions is performed in order to preserve as much of the periprostatic neurovascular tissue as possible $(11,18)$. The mobilisation of the apex NVB is only performed $5 \mathrm{~mm}$ beyond the urethra-prostate junction to avoid devascularisation or de-innervation of the sphincter active urethra. The length of urethra exposure is only enough to allow subsequent insertion of sutures for the urethra-vesical anastomosis after removal of the prostate.

Thereafter blunt mobilisation of the NVB off the posterior apex is performed and the posterior prostate fascia is bluntly divided to expose the perirectal fat at the apex. A fine long sucker, such as a modified carotid sucker, can be placed gently between the NVB and prostate to facilitate visualisation of the apex dissection. The prostate apex should now be exposed laterally with the anterior and lateral surface of the DVC exposed.

\section{$D V C$}

Control of the DVC is recognised as one of the key components to performing RP. In 1979, Reiner and Walsh described the anatomy of the DVC and a technique for its early ligation during retropubic RP (5). While good haemostasis promotes a clear operative field for the surgeon, poor control can result in bleeding severe enough to cause exsanguination $(5,17)$. Different methods have been described to control the DVC with or without dissecting the puboprostatic ligaments (17).

The principles of DVC division are minimising blood loss, avoiding inadvertent capsular breach at the prostatic apex and limiting injury to the striated sphincter. An understanding of the anatomy is critical to the successful ligation and division of the DVC. Several techniques of DVC division have been described and two alternatives favoured by the authors are described.

Some surgeons "bunch" the DVC by grasping the complex as it courses over the junction between the bladder neck and prostatic base with a Babcock or Allis clamp, before suturing the DVC over the prostate. The authors personally just suture ligate the DVC mid-prostate with a figure of eight using $2 / 0 \mathrm{Vicryl}^{\circledR}$, taking care not to include the posterolateral tissue containing the lateral prostatic fascia and the NVBs.

The DVC is then bunched distally at the prostatic apex ventral to the urethra with a Babcock clamp, indicated by palpation of the IDC. A 2-0 Vicryl ${ }^{\circledR}$ suture on a CT-2 needle is passed distally to the end of the clamp and superior to the urethra. The clamp is removed and the
DVC is ligated and divided with diathermy, whilst cephalad retraction of the anterior prostate with a sponge stick and apical retraction using the tip of a sucker by the surgical assistant is performed (19). Careful attention to the anterior prostate and apical margin is made as the division of the DVC to the urethra is performed.

An alternative that some of the authors perform, is to pass a right-angled clamp beneath the DVC just distal to the apex, ventral to the urethra. This clamp is used to grasp a guiding 22-gauge surgical wire, brought beneath the DVC in order to guide division. The two ends of the wire are held with an artery forceps and the DVC lifted gently anteriorly. This separates the DVC complex from the urethra and prostate apex. Using the wire as a guide, the DVC can be suture ligated distal to the wire and then divided cephalad to the suture, with care given to avoid incision into the prostate apex with a number 15 scalpel using the wire as a guide. A 3/0 Monocryl ${ }^{\circledR}$ suture is inserted into the lateral edge of the DVC then the DVC is divided with the scalpel blade until the fascia of the external sphincter are visible (20). The DVC is then ligated with the suture already placed in the lateral DVC margin.

Burkhard stresses the importance of then clearly identifying the two membranous layers between which the DVC is positioned. The superficial membrane is the continuation of the endopelvic fascia (overlies anterior surface of DVC), whereas the deeper membrane is the fascia of the striated external sphincter (underlies posterior surface of DVC) (20). Identifying these layers ensures appropriate suture placement, adequate haemostasis and prevention of accidental incorporation of the sphincter complex (20). DVC bleeding should be addressed and secured prior to continuing with the procedure. Bleeding should be controlled with 2-0 or 3/0 absorbable sutures using a running suture technique incorporating laterally the cut pelvic fascial edges.

\section{Apical dissection and division of the anterior urethra}

The apical dissection is one of most crucial and difficult parts of the procedure. Care must be taken to divide the DVC and prostatic apex without compromising margin status or damaging either NVB through excessive traction, diathermy or inadvertent transection when performing nerve-sparing. Once the DVC is divided and secured, the apex should be directly visualized with gentle retraction of the prostate. Meticulous dissection near the urethra just below the apex is performed, avoiding damage to the 
NVBs running either side of the urethra ("Walsh's pillars") with traction or thermal injury. The NVB should already be separated from the urethra and apex junction as per the DVC mobilisation and division.

The urethral sphincter is $\mathrm{U}$-shaped and does not converge dorsally where connective tissue and elastic fibres can be found (9). The striated external sphincter fibres are attached to the surface of the distal prostatic apex (18). The striated fibres are then pushed away, where the longitudinal smooth muscle fibres can then be seen running into the prostate gland. As the angle between the prostate and the symphysis opens, the upper surface of the sphincter and its fibres sweeping toward prostate apex can be completely exposed (9). The tip of the apex should now be precisely visible and the incision of the urethra can be done exactly distal to apex, preserving the maximal length of the membranous urethra $(18,20)$. The urethra is divided obliquely with either Metzenbaum scissors or a number 15 scalpel blade as the apex of the prostate extends more distally on the lateral and posterior aspects of the urethra. The authors avoid use of diathermy during the urethra division. The posterior urethra should be left intact to avoid retraction of the urethral stump and to allow placement of the anterior anastomotic sutures within the exposed ventral edge.

\section{Placement of urethral sutures and division of posterior urethra}

Once the anterior two-thirds of the urethra are divided as described above, sutures for the vesicourethral anastomosis (VUA) are placed. The benefit of this approach allows excellent visualisation of the urethra.

Sutures of double-armed (or single-armed with later use of Mayo needle) 3-0 Monocryl $^{\circledR}$ on a 5/8 curved UR-6 needle incorporating the urethral mucosa and submucosa are placed at 1, 3,9 and 11 o'clock positions on the urethral stump and held in place using rubber-shod artery clamps. The artery clamps can then be laid out circumferentially or labelled to indicate position and wrapped or covered with a small drape to avoid disruption or pulling, according to surgeon preference. The Foley catheter can be grasped with Roberts or Kelly forceps and after lubricating the distal end, cut and pulled though the urethra with gentle cephalad traction. This then allows placement of the 5 and 7 o'clock sutures. In the ORP versus robot RP trial, the ORP surgeon used 12 sutures for the anastomosis placed in each clock hour position (10). The posterior urethra was divided after the anterior sutures were placed. This increased number of sutures and enabled IDC removal at 7 days with no difference in urine leak compared to a robotassisted laparoscopic anastomosis. Less urine leak and more anastomotic sutures also potentially decrease the risk of bladder neck contracture (BNC), consistent with the low rate of BNC in the ORP $v s$. robotic RP randomised trial (21).

The posterior third of the urethra and recto-urethralis can now be sharply divided to expose the posterior leaf of Denonvilliers' fascia. Avoidance of excessive cephalad retraction of the prostate with the catheter at this point is important to prevent traction injury to the NVBs. Extra caution should be given to the division of the posterior urethra as the NVB are in close proximity. The use of a right-angled clamp passed midway between the apex of the prostate and the urethra from both sides can facilitate urethral division without NVB disruption and avoiding accidental contralateral NVB damage.

The posterior plane between Denonvilliers' fascia and rectum can now be developed with a mixture of sharp and blunt dissection, ensuring the rectum is adequately dissected off without injury.

\section{Nerve-sparing}

Stage migration with PSA testing has resulted in a younger aged patient group undergoing RP for early detected, organ-confined cancers (22). This younger population has increased demand for improved functional outcomes following surgery and encouraged the use of nerve-sparing techniques (18). Nerve-sparing surgery aims to preserve the NVBs positioned laterally to the prostate, bilaterally or unilaterally according to patient and oncological factors (2).

Although the exact role of the "lateral" nerves in continence and erectile function are unclear, the preservation of all tissues between the peri-prostatic fascia and the endopelvic fascia has been proposed as a method to improve functional outcome (23-25). Due to a conscious or unconscious sensation of urine entering the membranous urethra, one theory is that of a spinal reflex or voluntary sphincter contraction, resulting in increased tone of the external urethral sphincter and pelvic floor (20). Nerve injury may therefore worsen stress urinary incontinence outcomes following RP $(2,25)$. Furthermore, the technique of sparing these nerves relies on the acceptance that the NVBs are uniformly positioned and symmetrical. However recent anatomical studies suggest that the classically described dorsolateral NVB are present in only $48 \%$ of cases, with the remaining nerves spread on the entire lateral aspect of the prostate without either localisation or bundle 
formation (25-27).

The two common approaches for performing nervesparing surgery include the interfascial and intrafascial approaches (2). Interfascial, being the more superficial of the two dissections, is a plane within the NVB between the endopelvic fascia and the prostatic fascia and is also known as partial nerve-sparing. The intrafascial approach, is within the prostatic fascia and directly adjacent to the prostatic capsule. This approach is also known as complete nervesparing as more fascial and theoretically nerve tissue is preserved (2).

Clearly a major concern with nerve-sparing is oncological compromise, hence appropriate patient selection for nervesparing is imperative. Of note, histological pT3a prostate cancer can only be diagnosed in the presence of attached periprostatic fascia to the prostate specimen, which is likely to be affected with an intrafascial nerve-sparing approach $(9,23)$. Thus, various criterion exist to guide surgeons as to when nerve-sparing can be performed, such as in patients with nonpalpable tumours, if mpMRI does not indicate a Prostate Imaging-Reporting and Data System (PI-RADS) 5 lesion laterally near the NVB, if biopsies do not show tumour close to the NVB, or if not more than one biopsy is positive on the ipsilateral side (28).

The high incision on the anterior portion of the prostatic fascia near the 10 and 2 o'clock positions performed during the initial apex dissection should be continued where safe and feasible, in order to preserve as much of the periprostatic neurovascular tissue as possible $(11,18)$. The NVB is then gently pushed laterally and downward using a peanut or blunt scissors laterally and continued toward the apex, without any coagulation or ultrasound dissector to avoid inadvertent nerve damage (18). The bundles should be released completely requiring incision posteriorly through Denonvilliers' fascia. If bleeding occurs, this should be controlled with clips run parallel to the bundle in order to prevent inadvertent damage to the nerves or directed selective sutures $(18,20)$.

\section{Ligation of lateral prostatic pedicles, dissection of vas and seminal vesicles (SVs) and completion of prostatectomy}

Once adequate nerve release has been performed the prostate is retracted cephalad to expose the posterior plane of dissection, including Denonvilliers' fascia overlying the vas and SVs. Sequential division of the lateral vascular pedicles of the prostate is carried out by placing right angle clamps medially and creating windows between the prostate and the pedicle. The pedicles can then be secured using clips or suture ties and divided. These lateral pedicles are generally very vascular and thick, and thus should be divided in parts to avoiding bleeding. Posterior dissection should continue until the bladder neck and SVs.

The fascia overlying the SVs and ampulla of the vasa should be opened and the structures identified. The vasa are found medially and should be clipped and divided. Lateral dissection reveals the SVs and a combination of sharp and blunt dissection should free the vesicles. Arterial vascular supply to the SVs needs to be identified, controlled with Ligaclips ${ }^{\circledR}$ and divided in order to prevent problematic bleeding and pelvic hematoma. To avoid injury to the NVB, small clips, especially at the vesicle tips should be utilised. Once again, no diathermy is utilised in this area.

Once the pedicles and vasa are divided and SVs are free, the bladder neck can be divided from the prostate with diathermy, ensuring the ureteric orifices (UOs) are clear of dissection. Varying degrees of bladder neck preservation can be employed, with no significant benefit demonstrated for continence outcomes with bladder neck preservation, potentially at the expense of positive surgical margins (PSMs) (29).

\section{Bladder neck reconstruction (BNR)}

In most cases, some degree of BNR may be required to complete the VUA. The bladder mucosa is everted to allow mucosa to mucosa apposition with four to six interrupted 4-0 absorbable sutures. A posterior racket handle reconstruction technique is preferred by the authors. This can be performed with continuous or interrupted sutures and has the advantage of migrating the UOs away from the VUA during reconstruction, thereby lessening the risk of ureteric injury during the anastomosis.

Tolkach et al. report two methods of BNR-the "standard" technique as well as a modification that they perform. Description of the standard method of the BNR involves eversion of the bladder mucosa and bladder neck narrowing using a running 2-0 absorbable suture from the posterior edge of the bladder neck opening, forming a cross section resembling a "tennis racket" $(30,31)$. The racket handle being the oversewn posterior bladder wall, with the narrowed bladder opening being the racket face. A single 2-0 Vicryl ${ }^{\circledR}$ stitch is then used to approximate the dorsal part of the sphincter complex and the remaining portion of the vesico-prostatic muscle dorsal to the bladder neck (31). Tolkach et al. place an additional deep dorsal stitch with 0 Vicryl $^{\circledR}$ through all layers of the of the approximated posterior bladder wall. Placement of this 
deep dorsal stitch, further compresses the bladder neck opening by the surrounding tissues but without reducing the diameter of the orifice (31).

\section{Completion of anastomosis}

After the BNR, meticulous haemostasis is checked and secured in the pelvis and prostatic fossa. The use of surgical or other haemostatic agents can be used depending on the degree of haemostasis required and surgeon preference. The VUA is completed by reciprocally placing the 6-12 sutures attached to the urethral stump in corresponding positions on the reconstructed bladder neck. These sutures should be placed from inside to outside to ensure knots are tied outside the bladder, starting with the posterior sutures, followed by the lateral and finally anterior sutures. The IDC is advanced into the bladder and $15 \mathrm{~mL}$ placed in the balloon. The bladder is parachuted toward the urethra, ensuring that all sutures are correctly placed, without crossover or twisting, and cephalad retractors are released (with or without use of a Babcock clamp to hold the bladder towards the urethra). To reduce any tension on the bladder, the bed can be flattened and rarely the bladder needs to be released from its peritoneal attachments for large prostates. The sutures are tied from anterior to posterior or posterior to anterior depending on surgeon preference, and the anastomosis is completed. The IDC should be irrigated to perform a leak test to $100-150 \mathrm{~mL}$ volume and should be aspirated to ensure patency and remove any blood clots from the bladder.

\section{Additional haemostatic measures}

Blood loss during ORP can be substantial and any measure that helps reduce blood loss, in addition to early control of the DVC, may be a useful adjunct for the surgeon (32). When bleeding is properly controlled, the surgeon can focus on complete excision of the cancer, preservation of the sphincter mechanism, and appropriate sparing of the NVBs (11). Carvalhal et al. advocate "prophylactic" periprostatic haemostatic sutures prior to fully mobilising the prostate gland (32). They place 4.0 sutures in the anterior portions of the distal NVB and apical prostatic pedicles immediately after the urethra is transected (32). These sutures are tied with the least possible tension to obtain haemostasis while potentially minimising tissue injury (32). Despite being an additional step to the operation, the group did not find an overall increase in operative time likely due to reduced time achieving haemostasis once the prostate gland was removed. In their initial series of 200 patients, the mean estimated blood loss was significantly reduced from 1,285 to $<700 \mathrm{~mL}$ using these sutures (32). Burkhard et al. place a continuous 2.0 PDS suture in the bed of the SVs (20). An additional means to reduce blood loss is to have the patient in the Trendelenburg position to lower the venous pressure of the operation site (18).

In the opinion of the authors however, the priority for the patient is unlikely to be the avoidance of the shortterm requirement for blood transfusion (autologous or otherwise), compared to long term cancer cure and functional outcomes such as continence and erectile function which will persist long after the postoperative period. Using a cell saver, where available, will decrease the requirement for non-autologous blood products to $4 \%$ (10).

\section{Wound closure and placement of drain}

A 15-19 Fr Blake's drain is commonly placed into the pelvis, secured to the skin with non-absorbable suture and placed on suction according to surgeon preference. The wound should be closed in layers according to surgeon preference. The IDC should be secured to the patient's leg or abdomen to reduce risk of traction and VUA disruption.

\section{Peri-operative complications and outcomes}

In treating prostate cancer, urologists are faced with a unique challenge of combining good oncological outcomes with quality of life outcomes (33-36). The median life expectancy following curative treatment for prostate cancer is greater than 10 years (37). Therefore, optimising longterm functional outcomes are crucial for men's postsurgery quality of life. The most common post-operative compilations include long term erectile dysfunction (ED) and incontinence which have a significant negative impact on patient quality of life (33-36).

There is an absence of standardised reporting of surgical complication following ORP, resulting in wide variation of reported complications. These complications include bleeding, blood transfusion, rectal injury, urinary leak, ureteral injury, wound infections, pulmonary emboli, myocardial infarction, pneumonia and infected lymphoceles.

Bleeding is a well-established and significant intra operative complication when performing ORP $(32,38)$ most commonly encountered when dividing the DVC $(17,20)$. With increasing anatomical understanding and advances in surgical technique, the incidence of serious bleeding has reduced but remains an important consideration $(8,17,20)$. 
Large series of ORP have reported mean intra-operative blood loss from $500 \mathrm{~mL}$ to $>2 \mathrm{~L}$, and is likely dependent on operative technique, presence or absence of nerve-sparing, experience of the surgeon and operative time $(10,38,39)$. Perioperative blood transfusion rates are also varied, ranging from approximately $2 \%$ to $20 \%$ across various series and as high as $50 \%$ in a single institute $(5,10,33,36,39-43)$. The use of an intra-operative cell salvage system may reduce blood transfusion requirements without oncologic compromise $(10,44)$.

Significant peri-operative complications rates are low following ORP. Various large series report significant Clavien III-V complication ranging from as low as $1 \%$ to $12.9 \%$ $(10,33,42)$. Ficarra et al. reported an overall complication rate of up to $50 \%$ in a systematic review (40). A large retrospective series aimed to review ORP complications of 4,592 consecutive patients using a standardised reporting tool. The overall incidences of early minor and major complications for RP were $8.5 \%$ and $1.5 \%$ for medical and $11.4 \%$ and $4.9 \%$ for surgical complications (35).

\section{ED}

ED is the most common long term post-operative complication for men undergoing ORP (34). Pompe et al. report a significant decrease in useable erections in 8,573 consecutive cases (34). At baseline 78.4\% reported useable erections, significantly decreasing to $33.6 \%$ at 3 months, and slowly increasing to $44.7 \%, 51.1 \%$, and $52.6 \%$ at 12 , 24 , and 36 months after ORP. In patients with bilateral nerve-sparing $(\mathrm{n}=2,795)$, ED rates were $40.0 \%, 55.4 \%$, $62.7 \%$, and $65.7 \%$ at 3,12, 24 and 36 months. In this study $14 \%$ of all patients reported a negative effect and $13 \%$ reported problems in their relationships due to impaired sex function. In this cohort however at 2 years, $80 \%$ were satisfied with sexual intercourse (34).

The LAPPRO study reported erectile recovery rates of $44 \%$ and $53 \%$ at 12 and 24 months for D'Amico low and intermediate risk and $19 \%$ and $23 \%$ respectively for high risk cancers (45). In another series, ED was observed in $74.7 \%$ after retropubic radical prostatectomy (RRP) at 12 months (46). In the ProtecT trial only $15 \%$ of patients had adequate erections for intercourse at 1 year post RRP (47), while in the Prostate Cancer Outcomes Study (PCOS), which was mostly an older cohort, ED was nearly universal at 15 years, with $87.0 \%$ of those in the prostatectomy group reporting an inability to achieve an erection sufficient for intercourse (48).

In the ORP vs. robot assisted laparoscopic randomised trial, $71 \%$ of men were sexually active at baseline, including $59 \%$ more than half the time or always (10). Two years post ORP these figures decreased to $56 \%$ and $36 \%$ respectively (21). Hence, with attention to technical detail during the NVB preservation, approximately $60 \%$ of men can recover pre-existing erectile function, with or without the use of phosphodiesterase (PDE) inhibitors.

\section{Incontinence}

Incontinence is the most feared and frustrating complication of RRP for patients and clinicians. There is no universally agreed-upon definition of urinary continence, hence the definition of incontinence and method of data collection is important when interpreting manuscript results. For instance, Lepor and Kaci correlated responses to validated questionnaires assessing level of post-prostatectomy continence and patients, self-assessment of continence (5). Contemporary surgical series report rates of continence ranging from $80 \%$ to $97 \%(1,3,5,49)$.

At 2 years following surgery, $100 \%$ of men who reported occasional urinary leakage, or using a single protective pad over 24 hours, considered themselves continent (5). Therefore, some "continent" men may experience further improvement in continence over time. Glickman and colleagues reported that almost one-quarter of continent men reported subjective improvements in continence between 2 and 4 years after ORP (50).

Post prostatectomy, $9.6 \%$ of men reported no control or frequent leaking at 2 years in the PCOS study. This rate was as high as $18.3 \%$ at 15 years post procedure (48). Overall 26\% of RP patients within the Prostate Testing for Cancer and Treatment (ProtecT) trial suffered from urinary incontinence (use of any absorbent pads) at 12 months (47). Similarly, results from the Scandinavian Prostatic Cancer Group Study Number 4 showed urinary incontinence rates up to $43 \%$ (any use of protection aid) 1 year after ORP (51). Pompe et al. reported urinary continence rates of $75 \%$, $89.1 \%, 91.3 \%$ and $89 \%$ at 3, 12,24 and 36 months postORP (34). In this cohort, severe incontinence (defined as 3 or more pads per 24 hours) was rare with $5.1 \%, 2.9 \%, 2.3 \%$, and $2.1 \%$ at $3,12,24$ and 36 months post-ORP (34). At 12 months after ORP $20.2 \%$ of patients were continent in a prospective cohort of 778 ORP (46).

Finally, based on the techniques outlined in the randomised trial, the prevalence of incontinence in the ORP cohort, based on independent patient reported outcomes of no pad use, showed $66 \%$ of men were pad free at 3 months (10). This improved to $95 \%$ pad free at 24 months of follow-up (21). 
Table 1 Positive surgical margin rate post ORP in the literature (10,54-59)

\begin{tabular}{lcc}
\hline Study & $\mathrm{n}$ & PSM rate \\
\hline Sofer et al. J Urol 2002 & 734 & $29 \%$ \\
Blute et al. Urology 1997 & 2,712 & $26 \%$ \\
Eastham et al. Urology 2007 & 2,442 & $11.3 \%$ \\
Eastham et al. J Urol 2003 & 4,629 & $10 \%$ to $48 \%$ \\
Sachdeva et al. BMC Urol 2017 & 592 & $30.6 \%$ \\
Wright et al. J Urol 2010 & SEER 65,633 patients & $21.2 \%$ \\
Yaxley et al. Lancet 2016 & 163 & $10 \%$ \\
\hline
\end{tabular}

ORP, open radical prostatectomy; PSM, positive surgical margin.

\section{Psychological distress}

An increasingly recognised outcome of prostate cancer management is the psychological impact various treatment options may have on patients. Coughlin et al. identified one in five men in their study of robotic and ORP prostatectomy patients reporting increased psychological distress at 24 months postoperatively (21). Behavioural therapy can help men and their families cope with the distress of a prostate cancer diagnosis and potential subsequent treatment-related morbidity (52).

\section{Oncological outcomes}

The goal of RRP remains a good oncological result with clear surgical margins and prolonged cancer specific survival (CSS). In a systematic review, Berryhill et al. demonstrated a mean PSM rate of $23.5 \%$ for ORP, with the PSM rate for pT3 tumors being greater than that for pT2 tumors (53). Similar PSM rates are demonstrated in the literature (Table 1).

CSS has been demonstrated in three multicentre large randomised trials for organ-confined ORP. The SPCG4 study of 347 men with low and intermediate risk disease had a CSS of $84.9 \%$ at 18 years post ORP (51). Similar rates of CSS have been shown in the PIVOT and ProtecT studies with CSS of $91.5 \%$ at 19.5 years and $99 \%$ at 10 years respectively $(47,60)$. Again, these studies involved predominantly men with low to intermediate risk disease.

In a large SEER registry study of 65,633 patients, PSMs were reported in $21.2 \%$ and were more common in pT3a than pT2 tumors $(44 \%$ vs. $18 \%, \mathrm{P}<0.001)$ and higher grade tumors $(28 \%$ vs. $18 \%, \mathrm{P}<0.001)(59)$. The 7 -year diseasespecific survival rates for those at highest risk (higher grade, pT3a) were $97.3 \%$ for cases with negative surgical margins and $92.4 \%$ for those with PSMs. PSMs were associated with a 2.9-fold increased risk of prostate cancer specific mortality (59).

\section{Conclusion and future considerations}

Prostate cancer remains the second leading cause of cancer death in men (61). Treatment options for localised prostate cancer depend on a multitude of factors including the patients age, risk of prostate cancer progression, risk of mortality from other medical comorbidities, premorbid urinary function, sexual function and bowel function (62). While robot assisted laparoscopic prostatectomy is the most common radical surgical approach for prostatectomy performed in the USA, a recent Australian randomised clinical trial did not identify any significant difference in early urinary and sexual function or PSM rates when compared to the ORP $(10,21,63)$. Some urologists or physicians may conclude that this publication shows robotic technology does not add sufficient benefit to justify the increased medical cost. However, advocates of robotic prostatectomy recognise the shorter length of hospital stay, lower blood loss, less early postoperative pain, improved early physical and mental quality of life over the first 6-12 weeks and lower transfusion rates associated with the robotic approach $(10,64)$. Although both arms of the trial by Yaxley et al. involved a single surgeon, both were well versed and experienced in their respective surgical approach (ORP $v s$. robotic). The trial authors recognised that a multicentre, multi surgeon, randomised trial is the ultimate method of further investigating these different operative procedures. Financially, the likelihood of such large-scale study being undertaken would appear to be low however. The group subsequently reported a 24-month follow-up in which robotassisted laparoscopic prostatectomy showed a significantly 
lower crude rate of biochemical progression compared with ORP ( $3 \% v s .9 \%)$, although it is acknowledged that a difference in additional treatments before the PSA threshold of failure $(0.2 \mathrm{ng} / \mathrm{mL})$ may have influenced the biochemical progression results in the robot arm (21).

Although the trial by Yaxley et al. demonstrated comparable functional outcomes with ORP, it is unlikely that robot surgical units will return to the era of open surgery, given the level 1 evidence of the minimally invasive advantages of robot assisted laparoscopic surgery, providing the institutions can fund the robot technology (10). Additional to patient outcomes, the robotic approach to surgery may also result in reduced surgeon fatigue (64).

In conclusion, ORP remains a well-established surgical approach for the management of prostate cancer and will continue to be appropriately used in areas with financial limitations or with limited access to robotics. An increasing reliance on robotics however may result in a knowledge and experience gap in ORP and other open pelvic surgery. Training in ORP therefore should continue, in order to assist in the teaching of other open pelvic surgery (such as radical cystectomy) and so that it can be offered, were appropriate, to patients as a viable alternative to the robotic approach. It has been demonstrated that the quality and surgical technique of the surgeon is more important than the type of surgical procedure utilised.

\section{Acknowledgments}

Funding: The Translational Research Institute is supported by a grant from the Australian Government.

\section{Footnote}

Provenance and Peer Review: This article was commissioned by the Guest Editor (Shomik Sengupta) for the series "Surgery for Urologic Cancers" published in Translational Andrology and Urology. The article has undergone external peer review.

Conflicts of Interest: All authors have completed the ICMJE uniform disclosure form (available at http://dx.doi. org/10.21037/tau.2019.09.15). The series "Surgery for Urologic Cancers" was commissioned by the editorial office without any funding or sponsorship. The authors have no other conflicts of interest to declare.

Ethical Statement: The authors are accountable for all aspects of the work in ensuring that questions related to the accuracy or integrity of any part of the work are appropriately investigated and resolved.

Open Access Statement: This is an Open Access article distributed in accordance with the Creative Commons Attribution-NonCommercial-NoDerivs 4.0 International License (CC BY-NC-ND 4.0), which permits the noncommercial replication and distribution of the article with the strict proviso that no changes or edits are made and the original work is properly cited (including links to both the formal publication through the relevant DOI and the license). See: https://creativecommons.org/licenses/by-nc-nd/4.0/.

\section{References}

1. Catalona WJ, Carvalhal GF, Mager DE, et al. Potency, continence and complication rates in 1,870 consecutive radical retropubic prostatectomies. J Urol 1999;162:433-8.

2. Cornu JN, Phe V, Fournier G, et al. Fascia surrounding the prostate: clinical and anatomical basis of the nervesparing radical prostatectomy. Surg Radiol Anat 2010;32:663-7.

3. Kundu SD, Roehl KA, Eggener SE, et al. Potency, continence and complications in 3,477 consecutive radical retropubic prostatectomies. J Urol 2004;172:2227-31.

4. Roberts MJ, Papa N, Perera M, et al. Declining use of radical prostatectomy and pelvic lymphadenectomy despite more robotics: National population data over 15 years. Asia Pac J Clin Oncol 2020;16:e118-24.

5. Lepor H. A review of surgical techniques for radical prostatectomy. Rev Urol 2005;7 Suppl 2:S11-7.

6. Millin T. The surgery of prostatic obstructions. Ir J Med Sci 1947;(257):185-9.

7. Young $\mathrm{H}$. The cure of cancer of the prostate by radical perineal prostatectomy (prostato-seminal Vesiculectomy): History, Literature and Statistics of Young's Operation. J Urol 1945;53:188-252.

8. Walsh PC. Anatomic radical prostatectomy: evolution of the surgical technique. J Urol 1998;160:2418-24.

9. Stolzenburg JU, Schwalenberg T, Horn LC, et al. Anatomical landmarks of radical prostatecomy. Eur Urol 2007;51:629-39.

10. Yaxley JW, Coughlin GD, Chambers SK, et al. Robotassisted laparoscopic prostatectomy versus open radical retropubic prostatectomy: early outcomes from a randomised controlled phase 3 study. Lancet 2016;388:1057-66.

11. Eastham JA. Surgery Insight: optimizing open nervesparing radical prostatectomy techniques for improved 
outcomes. Nat Clin Pract Urol 2007;4:561-9.

12. Martis G, Diana M, Ombres M, et al. Retropubic versus perineal radical prostatectomy in early prostate cancer: eight-year experience. J Surg Oncol 2007;95:513-8.

13. Simon RM, Howard LE, Moreira DM, et al. Predictors of operative time during radical retropubic prostatectomy and robot-assisted laparoscopic prostatectomy. Int J Urol 2017;24:618-23.

14. Bartsch G, Horninger W, Klocker H, et al. Tyrol Prostate Cancer Demonstration Project: early detection, treatment, outcome, incidence and mortality. BJU Int 2008;101:809-16.

15. Roberts MJ, Papa N, Perera M, et al. A contemporary, nationwide analysis of surgery and radiotherapy treatment for prostate cancer. BJU Int 2019;124:31-6.

16. Davies BJ, Chung SY, Nelson JB. Delayed intraoperative hydration limits blood loss during radical retropubic prostatectomy. Urology 2004;64:712-6.

17. Atan A, Tuncel A, Polat F, et al. Seperation of dorsal vein complex from the urethra by blunt finger dissection during radical retropubic prostatectomy. Turk J Urol 2015;41:108-11.

18. Graefen M, Walz J, Huland H. Open retropubic nervesparing radical prostatectomy. Eur Urol 2006;49:38-48.

19. Eastham J, Tokuda Y, Scardino P. Trends in radical prostatectomy. Int J Urol 2009;16:151-60.

20. Burkhard FC, Kessler TM, Fleischmann A, et al. Nerve sparing open radical retropubic prostatectomy-does it have an impact on urinary continence? J Urol 2006;176:189-95.

21. Coughlin GD, Yaxley JW, Chambers SK, et al. Robotassisted laparoscopic prostatectomy versus open radical retropubic prostatectomy: 24-month outcomes from a randomised controlled study. Lancet Oncol 2018;19:1051-60.

22. Salinas CA, Tsodikov A, Ishak-Howard M, et al. Prostate cancer in young men: an important clinical entity. Nat Rev Urol 2014;11:317-23.

23. Khoder WY, Waidelich R, Buchner A, et al. Prospective comparison of one year follow-up outcomes for the open complete intrafascial retropubic versus interfascial nervesparing radical prostatectomy. Springerplus 2014;3:335.

24. Sievert KD, Hennenlotter J, Laible I, et al. The periprostatic autonomic nerves--bundle or layer? Eur Urol 2008;54:1109-16.

25. Stolzenburg JU, Kallidonis P, Do M, et al. A comparison of outcomes for interfascial and intrafascial nerve-sparing radical prostatectomy. Urology 2010;76:743-8.

26. Kiyoshima K, Yokomizo A, Yoshida T, et al. Anatomical features of periprostatic tissue and its surroundings: a histological analysis of 79 radical retropubic prostatectomy specimens. Jpn J Clin Oncol 2004;34:463-8.

27. Walz J, Burnett AL, Costello AJ, et al. A critical analysis of the current knowledge of surgical anatomy related to optimization of cancer control and preservation of continence and erection in candidates for radical prostatectomy. Eur Urol 2010;57:179-92.

28. Kessler TM, Burkhard FC, Studer UE. Nerve-sparing open radical retropubic prostatectomy. Eur Urol 2007;51:90-7.

29. Deliveliotis C, Protogerou V, Alargof E, et al. Radical prostatectomy: bladder neck preservation and puboprostatic ligament sparing--effects on continence and positive margins. Urology 2002;60:855-8.

30. Seaman EK, Benson MC. Improved continence with tubularized bladder neck reconstruction following radical retropubic prostatectomy. Urology 1996;47:532-5.

31. Tolkach Y, Godin K, Petrov S, et al. A new technique of bladder neck reconstruction during radical prostatectomy in patients with prostate cancer. Int Braz J Urol 2015;41:455-65.

32. Carvalhal GF, Griffin CR, Kan D, et al. Reducing blood loss in open radical retropubic prostatectomy with prophylactic periprostatic sutures. BJU Int 2010;105:1650-3.

33. Carlsson S, Nilsson AE, Schumacher MC, et al. Surgeryrelated complications in 1253 robot-assisted and 485 open retropubic radical prostatectomies at the Karolinska University Hospital, Sweden. Urology 2010;75:1092-7.

34. Pompe RS, Tian Z, Preisser F, et al. Short- and Long-term Functional Outcomes and Quality of Life after Radical Prostatectomy: Patient-reported Outcomes from a Tertiary High-volume Center. Eur Urol Focus 2017;3:615-20.

35. Rabbani F, Yunis LH, Pinochet R, et al. Comprehensive standardized report of complications of retropubic and laparoscopic radical prostatectomy. Eur Urol 2010;57:371-86.

36. Rassweiler J, Seemann O, Schulze M, et al. Laparoscopic versus open radical prostatectomy: a comparative study at a single institution. J Urol 2003;169:1689-93.

37. Tward JD, Lee CM, Pappas LM, et al. Survival of men with clinically localized prostate cancer treated with prostatectomy, brachytherapy, or no definitive treatment: impact of age at diagnosis. Cancer 2006;107:2392-400.

38. Djavan B, Agalliu I, Laze J, et al. Blood loss during radical prostatectomy: impact on clinical, oncological and functional outcomes and complication rates. BJU Int 2012;110:69-75. 
39. Augustin H, Pummer K, Daghofer F, et al. Patient selfreporting questionnaire on urological morbidity and bother after radical retropubic prostatectomy. Eur Urol 2002;42:112-17.

40. Ficarra V, Novara G, Ahlering TE, et al. Systematic review and meta-analysis of studies reporting potency rates after robot-assisted radical prostatectomy. Eur Urol 2012;62:418-30.

41. Koch MO. Robotic versus Open Prostatectomy: End of the Controversy. J Urol 2016;196:9-10.

42. Leow JJ, Chang SL, Meyer CP, et al. Robot-assisted Versus Open Radical Prostatectomy: A Contemporary Analysis of an All-payer Discharge Database. Eur Urol 2016;70:837-45.

43. Salomon L, Levrel O, de la Taille A, et al. Radical prostatectomy by the retropubic, perineal and laparoscopic approach: 12 years of experience in one center. Eur Urol 2002;42:104-10; discussion 110-1.

44. Kinnear N, O'Callaghan M, Hennessey D, et al. Intraoperative cell salvage in urological surgery: a systematic review and meta-analysis of comparative studies. BJU Int 2019;123:210-9.

45. Thorsteinsdottir T, Stranne J, Carlsson S, et al. LAPPRO: a prospective multicentre comparative study of robotassisted laparoscopic and retropubic radical prostatectomy for prostate cancer. Scand J Urol Nephrol 2011;45:102-12.

46. Haglind E, Carlsson S, Stranne J, et al. Urinary Incontinence and Erectile Dysfunction After Robotic Versus Open Radical Prostatectomy: A Prospective, Controlled, Nonrandomised Trial. Eur Urol 2015;68:216-25.

47. Hamdy FC, Donovan JL, Lane JA, et al. 10-Year Outcomes after Monitoring, Surgery, or Radiotherapy for Localized Prostate Cancer. N Engl J Med 2016;375:1415-24.

48. Resnick MJ, Koyama T, Fan KH, et al. Long-term functional outcomes after treatment for localized prostate cancer. N Engl J Med 2013;368:436-45.

49. Trock BJ, Han M, Freedland SJ, et al. Prostate cancerspecific survival following salvage radiotherapy vs observation in men with biochemical recurrence after radical prostatectomy. JAMA 2008;299:2760-9.

50. Glickman L, Godoy G, Lepor H. Changes in continence and erectile function between 2 and 4 years after radical prostatectomy. J Urol 2009;181:731-5.

51. Bill-Axelson A, Holmberg L, Ruutu M, et al. Radical prostatectomy versus watchful waiting in early prostate cancer. N Engl J Med 2011;364:1708-17.

52. Litwin MS, Tan HJ. The Diagnosis and Treatment of
Prostate Cancer: A Review. JAMA 2017;317:2532-42.

53. Berryhill R Jr, Jhaveri J, Yadav R, et al. Robotic prostatectomy: a review of outcomes compared with laparoscopic and open approaches. Urology 2008;72:15-23.

54. Sofer M, Hamilton-Nelson KL, Civantos F, et al. Positive surgical margins after radical retropubic prostatectomy: the influence of site and number on progression. J Urol 2002;167:2453-6.

55. Blute ML, Bostwick DG, Bergstralh EJ, et al. Anatomic site-specific positive margins in organ-confined prostate cancer and its impact on outcome after radical prostatectomy. Urology 1997;50:733-9.

56. Eastham JA, Kattan MW, Riedel E, et al. Variations among individual surgeons in the rate of positive surgical margins in radical prostatectomy specimens. J Urol 2003;170:2292-5.

57. Eastham JA, Kuroiwa K, Ohori M, et al. Prognostic significance of location of positive margins in radical prostatectomy specimens. Urology 2007;70:965-9.

58. Sachdeva A, Veeratterapillay R, Voysey A, et al. Positive surgical margins and biochemical recurrence following minimally-invasive radical prostatectomy - An analysis of outcomes from a UK tertiary referral centre. BMC Urol 2017;17:91.

59. Wright JL, Dalkin BL, True LD, et al. Positive surgical margins at radical prostatectomy predict prostate cancer specific mortality. J Urol 2010;183:2213-8.

60. Wilt TJ, Brawer MK, Jones KM, et al. Radical prostatectomy versus observation for localized prostate cancer. N Engl J Med 2012;367:203-13.

61. Siegel RL, Miller KD, Jemal A. Cancer statistics, 2018. CA Cancer J Clin 2018;68:7-30.

62. Barocas DA, Alvarez J, Resnick MJ, et al. Association Between Radiation Therapy, Surgery, or Observation for Localized Prostate Cancer and Patient-Reported Outcomes After 3 Years. JAMA 2017;317:1126-40.

63. Tsui C, Klein R, Garabrant M. Minimally invasive surgery: national trends in adoption and future directions for hospital strategy. Surg Endosc 2013;27:2253-7.

64. Fossati N, Wiklund P, Rochat CH, et al. Robotic and Open Radical Prostatectomy: The First Prospective Randomised Controlled Trial Fuels Debate Rather than Closing the Question. Eur Urol 2017;71:307-8.

Cite this article as: Pereira R, Joshi A, Roberts M, Yaxley J, Vela I. Open retropubic radical prostatectomy. Transl Androl Urol 2020;9(6):3025-3035. doi: 10.21037/tau.2019.09.15 